\title{
Cultural Factors Influencing International Collaborative Software Engineering Education in China
}

\author{
Yuqing Wang, Jouni Markkula \\ M3S Research Unit \\ University of Oulu, Finland \\ \{yuqing.wang, jouni.Markkula\}@oulu.fi
}

\author{
Jing Jiang \\ Nanjing Institute of Technology, China \\ jiangjing@njit.edu.cn
}

\begin{abstract}
Software engineering (SE) is a rapidly developing international discipline that requires up-to-date knowledge and skills. The need for well-educated professional software engineers is increasing globally. In China, universities are opening opportunities for collaboration and building cooperative relationships with Western universities in technology fields, including $\mathrm{SE}$, to offer Chinese students possibilities for international education in China instead of studying abroad. Designing high-quality $\mathrm{SE}$ education in international collaborative programs faces challenges introduced by cultural factors that affect learning practices. In this study, we addressed these challenges in the context of international collaborative SE education in China. In the first step, we synthesized existing knowledge of Chinese cultural factors affecting learning by conducting a systematic literature review (SLR). In the second step, we conducted interviews with SE students and teachers in a Chinese university that is preparing an international collaborative SE program, in order to see whether the identified cultural factors are valid in the current learning contexts of SE education. The results revealed that many of the identified factors are still valid, but some of them present differently in the current context because of the novelty of the SE discipline and the changing educational environment in China.
\end{abstract}

Keywords-software engineering education; Chinese culture; international collaborative education; cross-cultural education

\section{INTRODUCTION}

The demand for software engineers is increasing. Information and communication technology is extending to all areas of life, and technology innovations are increasingly introduced via software instead of hardware. Software engineering (SE) will play a critical role in future economic and social growth [1]. Higher education institutions are entrusted with the important role of cultivating the growing number of needed SE professionals with contemporary knowledge of the discipline and high innovation ability.

With the pace of globalization, international boundaries are fading. Recent years have witnessed Chinese government is boosting opportunities to gain advanced knowledge and develop new technologies, by opening up universities and building cooperative relationships with Western leading universities [2]. This cooperation model is referred as international collaborative education and is increasing in higher education contexts [3]. According to a statistic [4], approximately 30 international collaborative education programs between Chinese and Western universities were approved to being operated this year.

As a rapidly evolving global discipline, SE education is following the trend of adapting the programs into international collaborative education model in China. In international collaborative SE education programs in China, Western universities participate in curriculum and education design, as well as teach Chinese SE students [5]. However, these students have the different cultural backgrounds, which may affects education and learning. Western universities and Chinese SE students are likely to face cross-cultural challenges introduced by cultural factors that affect learning and learning practices. Those cultural challenges can be, for example, language barriers, different policies and practices, and different expectations about the roles of teachers and students [6].

In the extant literature, cultural factors have been widely studied in Chinese culture research, as well as education research. However, SE education differs from other educational disciplines; it is a relatively new, global, and rapidly developing area. This paper investigates the connection between cultural studies and SE education research, with the objective of identifying the Chinese cultural factors that characterize teacher-student interaction patterns in undergraduate SE education in China. Understanding these cultural factors and their effects on SE education is crucial to establish effective and suitable teacher-student interaction patterns in learning contexts, and therefore contributes to the successful design of international collaborative SE education programs between Western and Chinese universities.

The study was organized in two stages. In the first stage, the cultural factors that characterize teacher-student interaction patterns in Chinese learning contexts were identified through a systematic literature review (SLR). The second step examined those identified cultural factors in the current contexts of Chinese undergraduate SE education 
through interviews with students and teachers from Nanjing Institute of Technology (NJIT). NJIT is currently cooperating with the University of Oulu, Finland, to prepare an international collaborative SE education program. The target learners are undergraduate SE students in NJIT.

The paper is organized as follows: Section II gives an overview of relevant background information. Section III introduces the research questions and methods. Section IV presents the results. Section V analyzes the findings. Section VI discusses threats to the validity of the present study, and Section VII concludes the paper and discusses future work in this area.

\section{BACKGROUND}

This section presents the conceptual framework of our research. The focus of our study was international collaborative SE education in China and the cross-cultural challenges that may emerge in in intercultural contexts. When studying SE education in an international context, we should understand how SE and associated knowledge is specified in present-day global SE discipline, how learning can be studied and designed with systematic and integrated approaches, and how cross-cultural challenges can manifest in intercultural contexts.

\section{A. SE education in international context}

$\mathrm{SE}$ is formally described as "the application of a systematic, disciplined, quantifiable approach to the development, operation and maintenance of software; that is, the application of engineering to software" [7]. To define the scope of SE and ensure consistent understanding of it in international contexts, IEEE Computer Society (IEEE) has proposed a Software Engineering Body of Knowledge (SWEBOK). SWEBOK is used as the reference for SE curriculum development by academic institutions worldwide.

For undergraduate SE education, Association of Computing Machinery (ACM) and IEEE have published an international standard curriculum guide comprising ACM curriculum guidelines [8]. The guidelines define Software Engineering Education Knowledge (SEEK), which describe the body of knowledge that is appropriate for an undergraduate SE education program. On the basis of SWEBOK, SEEK uses a hierarchical organization dividing knowledge into three levels: knowledge areas, units, and topics. Though the guidelines describe which principles, knowledge, and practices SE education should cover, universities are advised to customize the content to design SE education programs based on their own requirements.

SE education specifies learning outcomes related to what students are able to know and do after learning. According to the ACM curriculum guidelines [8], an undergraduate SE program is recommended to include general learning outcomes. Students are expected to master, for example, professional knowledge and skills to work in the software industry; communication, negotiation, and cooperation skills to work in a team; and the ability to perceive changes and adjust to a changing environment.
To align education activities with learning outcomes in SE education, the cognitive domain of Bloom's Taxonomy is widely utilized. In Bloom's Taxonomy, the cognitive process contains six levels moving from the lowest level to the highest [9]. An undergraduate SE education program is expected to cover contents that range from Knowledge level to Application level [8]. This requires students to understand the principles, methods, and techniques related to SE, and apply those in software development practices. Moving from Knowledge level to Application level may require more active learning, innovative thinking and practical application experience [10].

\section{B. Learning framework for education}

In order to conceptualize leaning and understand how it can be organized by systematic and integrated approaches in education contexts, educational scientists have developed different learning frameworks. One of the comprehensive learning frameworks is Learning Environment, Learning Processes, and Learning outcomes (LEPO), which was proposed by Phillips et al. [11]. It was developed on the foundation of other popular learning models, such as Biggs's 3P model and Laurillard's conversational model. LEPO framework is considered as an appropriate tool for understanding how learning occurs in modern education. It aims to include all aspects about learning by integrating different learning models as a "whole." LEPO framework indicates that learning contains three components: Learning Environments, Learning Processes, and Learning Outcomes. Generally, learning environments are physical and virtual places where teaching and learning take place, for example, classrooms, laboratories, or web-based learning systems [11]. These also refer to contexts in which social and cultural aspects are embedded [12]. Learning processes refer to how learning takes place and incorporates the activities that lead to learning outcomes [13]. Learning outcomes reflect the results of learning [14]. These refer to measurable goals that students are able to achieve throughout learning processes [15]. The level of cognition that students can achieve is determined by the alignment of learning processes with learning outcomes [16].

Students and teachers are the two main groups of actors that interact across the three components of LEPO framework in learning situations. Students perform learning activities throughout the learning processes within learning environments to achieve the learning outcomes. Teachers are responsible for designing the learning environments by managing and controlling learning components such as the teaching model, teaching content, and supporting technologies [17]. They facilitate learning processes and determine the learning outcomes for students.

\section{Cross-cultural challenges in intercultural contexts}

Cross-cultural learning occurs in learning environments, in where cultures are mixed. Teachers and students are aware of and share culture through interaction [6]. The different cultural background may shape them differently from, for example, motivations, teaching behaviors and styles, learning behaviors and habits. Cultural conflicts may emerge in teacher-student 
interactions if teachers and students are culturally different [18]. Those conflicts are likely to influence how learning would be organized in learning process that lead to learning outcomes [11]. For example, if the ways students expect to learn are different with to what teachers provide, students may not be able to effectively perform learning activities to achieve the intended learning outcomes.

Al-Huwail et al. [19] identified the importance of policy and economic issues in cross-cultural learning design. Policy refers to the collection of rules, principles, and laws that determine how an education system operates [20]. For example, some countries have flexible and loose standards for curriculum development or learning strategies, while others have precise and centralized standards [21]. Economic issues impact the degree to which learning environments are supported by education resources.

\section{RESEARCH METHODOLOGY}

Based on the related research presented above, we specified our research questions as follows:

- $\quad$ RQ1: Based on prior research, what Chinese cultural factors influence teacher-student interaction patterns in Chinese learning contexts?

- RQ2: Do the identified Chinese cultural factors influence teacher-student interaction patterns in the current learning contexts of Chinese undergraduate SE education?

RQ1 was designed on the basis of the LEPO framework [11] to examine how prior researches define student and teacher roles influenced by cultural factors to characterize the expected teacher-student interaction patterns in Chinese learning environments. RQ2 links the identified Chinese cultural factors to Chinese SE education, and examines whether the cultural factors identified in previous literature are valid in the current learning contexts of undergraduate $\mathrm{SE}$ education in China.

The research process consists of two stages: a systematic literature review (SLR) and interviews. In the first stage, SLR was conducted to answer RQ1. In the second stage, interviews were conducted to collect empirical evidence to validate the findings from the SLR in the current learning context of undergraduate SE education in China. The interviews were also intended to gather deeper information to better understand and interpret cultural factors' effects on the specified context. The two research stages were expected to provide results that could be utilized in planning and implementing international collaborative SE education programs, in which Western and Chinese universities cooperate. A detailed description of the two research steps is presented below.

\section{A. Systematic literature review}

The SLR was conducted in May 2017, and it adapted the guidelines proposed by Kitchenham and Charters [22]. The review question is defined referring to the research question RQ1.

\section{1) Literature search}

The search process began with a preliminary search of different bibliographic databases to an initial understanding of the availability of relevant research. After this, two databases, ERIC (by ProQuest) and Academic Search Premier (EBSCO), were selected as sources for searching high quality literature. Informatics professionals were consulted in the selection of databases. ERIC is an authoritative database providing education and cultural studies literature and resources, while Academic Search Premier (EBSCO) is an authoritative multidiscipline database that covers high quality literature in a wide range of subjects such as SE, psychology, and cultural and regional studies.

The search string was formed based on key terms in the review question. The search string contains two parts. The design idea of the first part was: teacher-student interaction occurs in "teaching" and "learning" activities, and is influenced by "Chinese culture" in learning contexts. The design idea of the second part was: "students" and "teachers" are the main actors in teacher-student interaction, and their roles are guided by "Chinese culture". To extend the search, alternative terms and concepts addressing the same problems were considered. Those include taking singular/plural forms and verbal forms of key terms into account. For example, "learn*" is used to get literature that contains the key term such as "learn", 'learning', or 'leaners'; "student*" is used to get literature that contains the key term like "student" and "students"; and "Chinese cultur*" is used to get literature that contains the key terms like "Chinese culture" and "Chinese cultural factors". Pilot research was performed to examine whether the search would provide meaningful results. A few variations of the combination were tested to ensure the coverage and representativeness of the search. The final search string was defined as:

(("learn*" OR "teach*") OR ("student*" OR "teacher*”)) AND "Chinese cultur*"

\section{2) Primary study selection}

When applying the search string in the specified databases (covering "title", "keywords", and "abstract"), the result was 1425 publications in total (794 in ERIC and 631 in Academic Search Premier).

The publications were reviewed against inclusion and exclusion criteria (Table I). The whole selection process consisted of three rounds. The first round used metadata. In this step, the papers were screened based on publication quality and availability. This step led to 303 results from ERIC and 170 results from Academic Search Premier. In the second round, duplicate papers were removed, and the remaining publications were reviewed based on their titles, keywords, and abstracts to remove publications that were irrelevant with respect to the research question RQ1. If the relevance of the publication was not clear based on the title, keywords, and abstract, it was left for the next round. The third round performed light reading of the full text of each remaining article to select papers that contain empirical studies. It resulted in 21 publications, which were chosen as the primary studies. 
TABLE I. INCLUSION \& EXCLUSION CRITERIA

\begin{tabular}{|l|l|l|l|}
\hline Round & $\begin{array}{l}\text { Inclusion criteria } \\
\text { (If a paper) }\end{array}$ & $\begin{array}{l}\text { Exclusion } \\
\text { criteria } \\
\text { (If a paper) }\end{array}$ & $\begin{array}{l}\text { Total } \\
\text { numbers } \\
\text { after } \\
\text { selection }\end{array}$ \\
\hline 1 & $\begin{array}{l}\text { is published in a journal } \\
\text { AND is accessible }\end{array}$ & $\begin{array}{l}\text { is written in a } \\
\text { language other } \\
\text { than English } \\
\text { OR is an editorial, } \\
\text { abstract, or a short } \\
\text { paper }\end{array}$ & 473 \\
\hline 2 & $\begin{array}{l}\text { ind is peer reviewed } \\
\text { culture" and "roles of } \\
\text { teachers and students in } \\
\text { learning" or "learning } \\
\text { that occurs in learning } \\
\text { contexts in China" }\end{array}$ & $\begin{array}{l}\text { OR clearly outside } \\
\text { the scope of our } \\
\text { research } \\
\text { OR partly inside } \\
\text { the scope of our } \\
\text { research but is not } \\
\text { able to answer } \\
\text { RQ1 }\end{array}$ & \\
\hline 3 & $\begin{array}{l}\text { AND meets the criteria } \\
\text { of the second round } \\
\text { studies empirical }\end{array}$ & $\begin{array}{l}\text { contains } \\
\text { empirical data }\end{array}$ & 21 \\
\hline
\end{tabular}

\section{3) Classification and data extraction}

This process began with a further reading of all 21 primary studies. A classification scheme was created to extract data in an effective manner. The LEPO learning framework [11] was used as a reference to recognize teacher-student interaction in learning contexts. In addition, Hofstede's [18] cultural also was used to classify them into four cultural dimensions as classification themes: Power Distance, Collectivism versus Individualism, Masculinity versus Femininity, and Uncertainty Avoidance.

Based on the specified classification schemes, the following data was extracted from the primary studies: title of the paper, year of publication, authors, interaction of students and/or teachers related to cultural dimensions in learning, and other relevant findings such as the changing roles of teachers and students, the reasons to change, and other aspects relevant to the study. To maintain consistency, data extraction was performed using a standardized Excel form.

\section{B. Interviews}

The interviews were designed in the second stage of the study, according to the results of the SLR. The interviews were conducted in June 2017, with the purpose to answer research question RQ2.

\section{1) Interview design}

The interview themes were designed using the LEPO framework [11]. To create the themes, the cultural factors were linked with the LEPO learning components. Table II presents these themes. The semi-structured interview questions were designed relating to the key points and objective of each theme.
TABLE II. INTERVIEW THEMES

\begin{tabular}{|l|l|}
\hline Theme & Key points and objectives \\
\hline $\begin{array}{l}\text { Learning } \\
\text { environments }\end{array}$ & $\begin{array}{l}\text { Examine learning environments in the current context } \\
\text { of undergraduate SE education in China and perceive } \\
\text { relevant changes in recent years }\end{array}$ \\
\hline Learning processes & $\begin{array}{l}\text { Verify whether the cultural factors identified in the } \\
\text { SLR, relating to how students engage in learning and } \\
\text { how teachers facilitate learning processes, are valid in } \\
\text { the current context of undergraduate SE education in } \\
\text { China }\end{array}$ \\
\hline Learning outcomes & $\begin{array}{l}\text { Verify whether the identified cultural factors in the } \\
\text { SLR, relating to how teachers determine learning } \\
\text { outcomes that are achieved by students, are valid in } \\
\text { the current context of undergraduate SE education in } \\
\text { China }\end{array}$ \\
\hline $\begin{array}{l}\text { Relationships } \\
\text { between students } \\
\text { and teachers }\end{array}$ & $\begin{array}{l}\text { Verify whether the identified cultural factors in the } \\
\text { SLR, relating to interactions and relationships } \\
\text { between students and teachers, are valid in the } \\
\text { current context of undergraduate SE education in } \\
\text { China }\end{array}$ \\
\hline
\end{tabular}

To test and validate the interview guide, two pilot interviews, one with a student and one with a teacher, were conducted. The pilot interview results indicated that the designed of interviews could provide relevant and sufficient information to meet the purposes of the study. The interview questions were revised based on the received feedback.

\section{2) Interviewee recruitment}

The selected interviewees were SE students and teachers from the School of Computer Engineering at NJIT. After agreeing to conduct the interviews, NJIT recruited three teachers and five students for the interviews. The interviewed students, labeled as Student 1-5 in this paper, began their studying in the SE program at NJIT in different years. The interviewed teachers had varied teaching fields, years of teaching experience and genders. They are labeled as teacher $\mathrm{A}-\mathrm{C}$ in this paper.

\section{3) Interview process}

The duration of each interview was 20-50 minutes. To ensure accurate expression and the interviewees' preference, the interviews were conducted in Chinese. The interviewees were sent the interview guide in advance so they could familiarize themselves with the questions and prepare themselves for the interviews. The interviews were conducted via live video chat using QQ, which is a Chinese instant message application. Approval was requested from each interviewee to audio record the interview. The interviews followed the defined interview themes, but the themes were explored further with additional questions depending on the situation.

\section{4) Data collection and analysis}

Audio recordings of the interviews were transcribed verbatim. The assembled data were examined carefully in order to category them into themes. The analysis began with a comparison of interviewee-verified data with the findings of the SLR in order to examine whether the identified cultural factors from the SLR are valid in the current context of 
undergraduate SE education in China. Additional information was also explored to complement the findings of the SLR, for example, the reasons why the certain cultural factors are still valid or not valid in current contexts of undergraduate SE education.

\section{RESULTS}

In this section, the findings of the SLR and interviews are summarized to answer the research questions.

\section{A. Chinese cultural factors related to student-teacher interactions identified in the SLR}

The primary studies analyzed in the SLR are listed in Table III. Most of those papers were published in the last ten years. The earliest one was published in 1998, while the most recent one was published in 2016 . The research contexts range from preschool education to master's level education.

TABLE III. LIST OF PRIMARY STUDIES

\begin{tabular}{|c|c|c|c|}
\hline Reference & Year & Title & Authors \\
\hline [P002] & 1998 & $\begin{array}{l}\text { Student attitudes to text design and } \\
\text { tutorial activities: } \\
\text { consideration }\end{array}$ & K. Chao \\
\hline [P003] & 1999 & $\begin{array}{l}\text { Redefining the value structure of } \\
\text { college students in Hong Kong and } \\
\text { the mainland of China }\end{array}$ & $\begin{array}{l}\text { C. Cheng \& } \\
\text { S. Kwok }\end{array}$ \\
\hline [P020] & 2000 & $\begin{array}{l}\text { Constructing and validating a teacher } \\
\text { immediacy scale: A Chinese } \\
\text { perspective }\end{array}$ & $\begin{array}{l}\text { Q. Zhang \& } \\
\text { J. G. Oetzel }\end{array}$ \\
\hline [P012] & 2003 & $\begin{array}{l}\text { U.S. and Chinese cultural beliefs } \\
\text { about learning }\end{array}$ & J. Li \\
\hline [P014] & 2003 & $\begin{array}{l}\text { The flow model of intrinsic } \\
\text { motivation in Chinese: Cultural and } \\
\text { personal moderators }\end{array}$ & $\begin{array}{l}\text { G. B. } \\
\text { Moneta }\end{array}$ \\
\hline [P016] & 2005 & $\begin{array}{l}\text { Promoting independent learning } \\
\text { through language learning and the use } \\
\text { of IT }\end{array}$ & C. C. Shyh \\
\hline [P006] & 2006 & $\begin{array}{l}\text { Teachers' professional vulnerability } \\
\text { and cultural tradition: A Chinese } \\
\text { paradox }\end{array}$ & X. Gao \\
\hline [P007] & 2006 & $\begin{array}{l}\text { Who adapts? Beyond cultural models } \\
\text { of "the" Chinese learner }\end{array}$ & $\begin{array}{l}\text { Q. Gu \& M. } \\
\text { Schweisfurt } \\
\text { h }\end{array}$ \\
\hline [P013] & 2006 & $\begin{array}{l}\text { Crossing the cultural divide in early } \\
\text { childhood teacher education } \\
\text { programs: A study of Chinese } \\
\text { graduate students' perceptions of } \\
\text { American early care and education }\end{array}$ & $\begin{array}{l}\text { N. Luo \& J. } \\
\text { L. Gilliard }\end{array}$ \\
\hline [P017] & 2006 & $\begin{array}{l}\text { Achieving relationship harmony in } \\
\text { groups and its consequence for group } \\
\text { performance }\end{array}$ & $\begin{array}{lrr}\text { V. } & \text { M. } & \text { Lun } \\
\& & \text { M. } & \text { H. } \\
\text { Bond } & \end{array}$ \\
\hline [P009] & 2007 & $\begin{array}{l}\text { Emergence of Confucianism from } \\
\text { teachers' definitions of guidance and } \\
\text { discipline in Hong Kong secondary } \\
\text { schools }\end{array}$ & M. Hue \\
\hline [P015] & 2008 & $\begin{array}{l}\text { Understanding Chinese students' use } \\
\text { of language learning strategies from } \\
\text { cultural and educational perspectives }\end{array}$ & Z. Rao \\
\hline
\end{tabular}

\begin{tabular}{|c|c|c|c|}
\hline [P005] & 2010 & $\begin{array}{l}\text { Tensions and dilemmas of teachers in } \\
\text { creativity reform in a Chinese Context }\end{array}$ & $\begin{array}{l}\text { V. M. Y. } \\
\text { Cheng }\end{array}$ \\
\hline [P019] & 2011 & $\begin{array}{l}\text { Be passionate, but be rational as well: } \\
\text { Emotional rules for Chinese teachers' } \\
\text { work }\end{array}$ & $\begin{array}{l}\text { H. Yin \& J. } \\
\text { C. Lee }\end{array}$ \\
\hline [P011] & 2012 & $\begin{array}{l}\text { Adapting Western pedagogies for } \\
\text { Chinese literacy instruction: Case } \\
\text { studies of Hong Kong, Shenzhen, and } \\
\text { Singapore preschools }\end{array}$ & $\begin{array}{l}\text { H. Li, N. } \\
\text { Rao \& S. K. } \\
\text { Tse }\end{array}$ \\
\hline [P010] & 2013 & 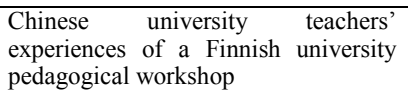 & $\begin{array}{l}\text { K. Kettula } \\
\text { et al. }\end{array}$ \\
\hline [P018] & 2013 & $\begin{array}{l}\text { Societal culture and teachers' } \\
\text { responses to curriculum reform: } \\
\text { Experiences from China }\end{array}$ & H. Yin \\
\hline [P021] & 2014 & $\begin{array}{l}\text { Self-regulated learning ability of } \\
\text { Chinese distance learners }\end{array}$ & $\begin{array}{l}\text { H. Zhao, L. } \\
\text { Chen \& S. } \\
\text { Panda }\end{array}$ \\
\hline [P004] & 2015 & $\begin{array}{l}\text { Chinese mindset: Theories of } \\
\text { intelligence, goal orientation and } \\
\text { academic achievement in Hong Kong } \\
\text { students }\end{array}$ & $\begin{array}{l}\text { W. Chen \& } \\
\text { Y. Wong }\end{array}$ \\
\hline [P001] & 2016 & $\begin{array}{l}\text { Understanding Chinese university } \\
\text { student conceptions of assessment: } \\
\text { Cultural similarities and jurisdictional } \\
\text { differences between Hong Kong and } \\
\text { China }\end{array}$ & Z. Rao \\
\hline [P008] & 2016 & $\begin{array}{l}\text { Applicability of the classroom } \\
\text { assessment scoring system in Chinese } \\
\text { preschools based on psychometric } \\
\text { evidence }\end{array}$ & $\begin{array}{l}\text { Hu, B. Y., } \\
\text { Fan, X., Gu, } \\
\text { C., \& Yang, } \\
\text { N }\end{array}$ \\
\hline
\end{tabular}

The summary of the studies presented in Table IV, identifies how many of them discuss cultural factors influencing teacher-student interaction. As the mainstream traditional culture, Confucian Heritage Culture (CHC) strongly influences the manifestation of Chinese culture in education contexts [P001, P003-P006, P009, P011, P012, P017]. Chinese learning contexts are influenced by High Power Distance, Collectivism, and Masculinity culture, to characterize student-teacher interaction patterns. However, different perspectives emerged concerning about Uncertainty Avoidance in Chinese culture, even though Hofstede [18] have indicated that China scores low in this area.

TABLE IV. IDENTIFIED CULTURAL FACTORS INFLUENCE TEACHERSTUDENT INTERACTION IN CHINESE LEARNING ENVIRONMENTS

\begin{tabular}{|l|l|l|}
\hline $\begin{array}{l}\text { Cultural } \\
\text { dimension }\end{array}$ & $\begin{array}{l}\text { Numbers } \\
\text { of papers }\end{array}$ & Citations of primary studies \\
\hline $\begin{array}{l}\text { High Power } \\
\text { Distance }\end{array}$ & 16 & $\begin{array}{l}{[\mathrm{P} 001],[\mathrm{P} 002],[\mathrm{P} 003],[\mathrm{P} 005],[\mathrm{P} 006],} \\
{[\mathrm{P} 007],[\mathrm{P} 008],[\mathrm{P} 009],[\mathrm{P} 010],[\mathrm{P} 011],} \\
{[\mathrm{P} 020]}\end{array}$ \\
\hline Collectivism & 13 & $\begin{array}{l}\text { [P001], [P002], [P003], [P007], [P008], } \\
\text { [P009], [P012], [P013], [P014], [P015], } \\
{[\mathrm{P} 017],[\mathrm{P} 018],[\mathrm{P} 019]}\end{array}$ \\
\hline Masculinity & 3 & {$[\mathrm{P} 018],[\mathrm{P} 004],[\mathrm{P} 021]$} \\
\hline $\begin{array}{l}\text { Weak } \\
\text { Uncertainty } \\
\text { Avoidance }\end{array}$ & 2 & {$[\mathrm{P} 014],[\mathrm{P} 019]$} \\
\hline
\end{tabular}




\section{1) High Power Distance \& collectivism}

High Power Distance and Collectivism orientation of Chinese culture could be traced to CHC. High Power Distance and Collectivism culture complement each other to emphasize social hierarchy, authority, discipline, and harmony [P011, P017, P020]. Table V shows the teacher-student interaction patterns related to those two cultural dimensions.

TABLE V. IDENTIFIED TEACHER-STUDENT INTERACTIONS RELATED TO HIGH POWER DISTANCE \& COLLECTIVISM

\begin{tabular}{|l|l|}
\hline $\begin{array}{l}\text { Cultural } \\
\text { dimension }\end{array}$ & $\begin{array}{l}\text { Teacher-student interaction and related primary } \\
\text { study citations }\end{array}$ \\
\hline $\begin{array}{l}\text { High power } \\
\text { distance }\end{array}$ & $\begin{array}{l}\text { Teacher-centered education - [P001], [P002], [P005], } \\
{[\mathrm{P} 007],[\mathrm{P} 009],[\mathrm{P} 010],[\mathrm{P} 011],[\mathrm{P} 016],[\mathrm{P} 019],[\mathrm{P} 018],} \\
{[\mathrm{P} 020],[\mathrm{P} 021]} \\
\text { Students respect teachers - [P002], [P006], [P008], } \\
{[\mathrm{P} 012],[\mathrm{P} 005],[\mathrm{P} 015],[\mathrm{P} 018],[\mathrm{P} 020]} \\
\text { Teachers define learning paths for students - [P002] }\end{array}$ \\
\hline Collectivism & $\begin{array}{l}\text { Students prefer to learn how to learn - [P002] } \\
\text { Students speak up in limited situations - [P005] } \\
\text { Formal harmony is maintained in learning situations - } \\
{[\mathrm{P} 005],[\mathrm{P} 017]} \\
\text { Teachers and students care about "face" - [P003] } \\
\text { Diploma certificates are important - [P007], [P013] } \\
\text { Education can help students to gain higher social status } \\
\text { and bring honor to their family - [P001], [P009], } \\
{[\mathrm{P} 012],[\mathrm{P} 013],[\mathrm{P} 015],[\mathrm{P} 019]} \\
\text { Enjoyment of collaboration and solidarity - [P018] }\end{array}$ \\
\hline
\end{tabular}

Teacher-centered education prevails in the majority of Chinese learning contexts [P002, P007, P009, P011, P019]. Students respect teachers and treat them as role models and mentors [P006, P005, P020]. Because of the large class size in Chinese schools, teacher-student interaction frequently happens in the whole-class model [P008, P010, P011]. Limited resources like short lecture hours and overloaded teaching decreases possibilities for more student-centered learning activities, while teacher-directed learning activities are highly promoted [P005, P010, P011, P019].

In collectivist societies that share $\mathrm{CHC}$, people emphasize harmony and try to build stable relationships with others [P017]. Students are not likely to challenge teachers' authority even when their opinions are different [P005]. Additionally, in connection to group work, students enjoy the solidarity of group collaborations and pay attention to group harmony. The arguments may not easy to being brought even though the different opinions exist in the group work [P005, P018]. Overall, formal harmony is maintained in most learning situations.

\section{2) Masculinity}

Chinese learning environments are highly driven by competition and achievement [P001, P003, P004, P011, P019, $\mathrm{P} 021]$. This reveals Masculine culture in learning contexts.
Identified teacher-student interactions related to this cultural dimension are presented in Table VI.

TABLE VI. IDENTIFIED TEACHER-STUDENT INTERACTIONS RELATED TO MASCULINE CULTURE

\begin{tabular}{|l|l|}
\hline $\begin{array}{l}\text { Cultural } \\
\text { dimension }\end{array}$ & $\begin{array}{l}\text { Teacher-student interaction and related primary } \\
\text { study citations }\end{array}$ \\
\hline Masculinity & $\begin{array}{l}\text { Students care about academic success - [P004] } \\
\text { Students compete in the learning environment - [P001], } \\
{[\mathrm{P} 004],[\mathrm{P} 021]}\end{array}$ \\
\hline
\end{tabular}

Chinese students feel pressure to attain academic success. This could be explained in connection to the education system and collectivist values. Chinese education is mostly examoriented and relies on public examinations [P001, P004, P011, $\mathrm{P} 015, \mathrm{P} 015]$. Exam-oriented education began in ancient times and continues in the present. In addition to personal growth and development, education is also considered as a way to obtain practical benefits like higher social status and family honor [P001, P002, P009, P015]. Moreover, the huge population seems to make competition more intense. In many circumstances, only small groups of people are able to get such benefits. It is the norm that students frequently compare themselves to others [P001]. People wish to surpass others to prove themselves through personal achievement [P004].

\section{3) Uncertainty Avoidance}

According to Hofstede's [18] cultural dimension theory, Chinese society is comfortable with ambiguous or unknown situations, and therefore is characterized as a Weak Uncertainty Avoidance country. However, the SLR results present more complexity in this area. Teacher-student interactions demonstrate both Weak and Strong Uncertainty Avoidance (Table VII).

TABLE VII. IDENTIFIED TEACHER-STUDENT INTERACTION RELATED TO UNCERTAINTY AVOIDANCE

\begin{tabular}{|l|l|}
\hline Weak Uncertainty Avoidance & Strong Uncertainty Avoidance \\
\hline $\begin{array}{l}\text { Students expect to have unstructured } \\
\text { learning experiences assigned with } \\
\text { vague learning objectives - [P014] }\end{array}$ & $\begin{array}{l}\text { Students expect to have structured } \\
\text { learning experiences assigned with } \\
\text { strict learning schedules and detailed } \\
\text { assignments - [P002], [P004], [P013] }\end{array}$ \\
$\begin{array}{l}\text { Teachers are expected to regulate } \\
\text { their emotions in accordance with } \\
\text { professional and ethical norms - } \\
\text { [P019] }\end{array}$ & $\begin{array}{l}\text { Teachers are supposed to have the } \\
\text { right the answers - [P005] }\end{array}$ \\
\hline
\end{tabular}

Though more results support Strong Uncertainty Avoidance culture, there is not conclusive evidence to indicate the specific role of Uncertainty Avoidance in teacher-student interaction patterns in Chinese learning contexts. It seems that more extensive research regarding this phenomenon is needed because of the contradictory results. 


\section{B. Validation of identified Chinese cultural factors through interviews}

The results of the interviews indicate that many cultural factors identified in the SLR are still valid in the current contexts of undergraduate SE education in China. However, some of them are not influential in the current learning contexts. The interviewees not only discussed their perceptions about the identified cultural factors but also went into the details regarding the reasons for their effects. The findings are discussed and analyzed according to the different cultural dimensions.

\section{1) High Power Distance \& Collectivism}

The interviews validated that High Power Distance and collectivism exist in the current learning contexts of undergraduate SE education. Fig. 1 shows the perceptions of interviewees concerning High Power Distance and Collectivism. It presents the interviewees' opinions on whether they consider the corresponding teacher-student interaction in each cultural dimension to be valid in current learning contexts of SE education. If the response was not clear, it was counted as "conditional".

\section{Numbers of responding interviewees: $\begin{array}{llllll}0 & 2 & 4 & 6 & 8\end{array}$}

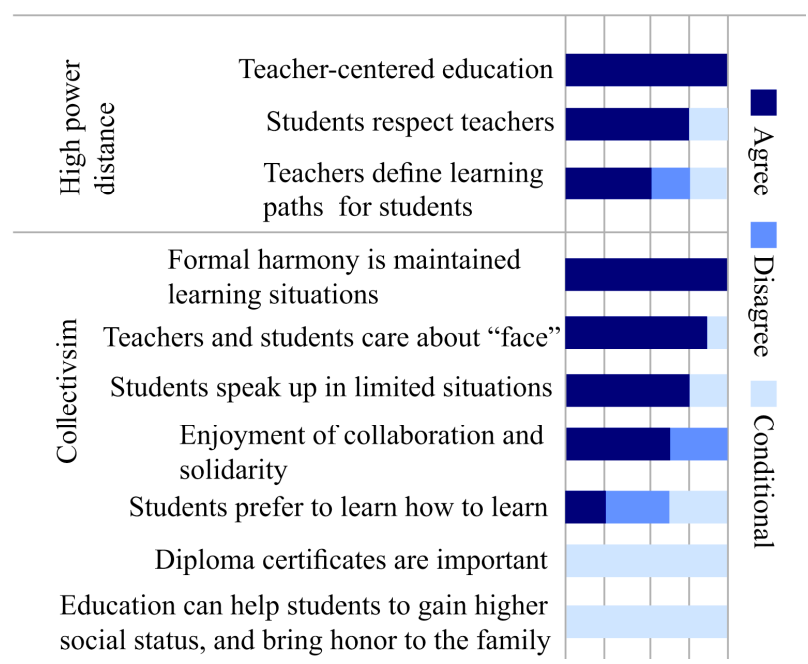

Fig. 1. Interviewees' perceptions related to high power distance and collectivism culture

Interviewees highly agree that "teacher-centered education", "students speak up in limited situations", "students respect teachers", "teachers and students care about "face", "formal harmony is maintained in learning situations", and "enjoyment of collaboration and solidarity" are valid in present undergraduate SE education. Table VIII shows example reflections from interviewees.
TABLE VIII. REFLECTIONS ON TEACHER-STUDENT INTERACTIONS

\begin{tabular}{|c|c|}
\hline Teacher-student interaction & Interviewee reflections \\
\hline $\begin{array}{l}\text { Teacher-centered education \& } \\
\text { students speak up in limited } \\
\text { situations }\end{array}$ & $\begin{array}{l}\text { "In theoretical courses, teachers outline } \\
\text { the important content of course book and } \\
\text { explain the key points. After class, ou can } \\
\text { contact teachers to ask questions if you } \\
\text { have problems. In experiment courses, } \\
\text { we will come to computer rooms or } \\
\text { laboratories to test what we learned from } \\
\text { theoretical courses." Student } 1 \\
\text { "Teachers stand in front of students and } \\
\text { give lectures using PowerPoint...they,, } \\
\text { will ask questions and let us answer." } \\
\text { Student } 3 \\
\text { "We mostly use traditional instruction } \\
\text { methods." Teacher B }\end{array}$ \\
\hline Students respect teachers & $\begin{array}{l}\text { "It is not a special case but just like you } \\
\text { respect others in normal life." Student } 3 \\
\text { "It is the tradition to respect the teacher } \\
\text { and his teaching...um... I think it is } \\
\text { mutual; students respect me, and I also } \\
\text { respect them." Teacher B }\end{array}$ \\
\hline $\begin{array}{l}\text { Teachers and students care about } \\
\text { "face" }\end{array}$ & $\begin{array}{l}\text { “Chinese care about 'face, 'more or } \\
\text { less.” Teacher A }\end{array}$ \\
\hline $\begin{array}{l}\text { Formal harmony is maintained in } \\
\text { learning situations }\end{array}$ & $\begin{array}{l}\text { "In most of cases, it is harmony." } \\
\text { Student } 4 \\
\text { "As I perceived we are harmony in most } \\
\text { of situations" Teacher C }\end{array}$ \\
\hline $\begin{array}{l}\text { Enjoyment of collaboration and } \\
\text { solidarity }\end{array}$ & $\begin{array}{l}\text { "Um...I probably like group work more. } \\
\text { Generally, group work is comprehensive. } \\
\text { It integrates lots of aspects...um... There } \\
\text { is distribution and collaboration among } \\
\text { team members." Student } 1 \\
\text { "No matter what kinds of teachers we } \\
\text { are, we have the common goal of } \\
\text { collaborating together to help students to } \\
\text { learn new things." Teacher B }\end{array}$ \\
\hline
\end{tabular}

The opinions of students vary greatly regarding learning styles related to "teachers define learning paths for students" and "students prefer to learn how to learn" (Table IX). In interviews with teachers, possible reasons for this emerged. Students are used to depending on teachers from their previous learning experience, but they would change their styles in order to achieve the expected learning outcomes in SE education.

TABLE IX. REFLECTIONS ON LEARNING STYLES

\begin{tabular}{|c|c|}
\hline Responses from students & Response from a teacher \\
\hline $\begin{array}{l}\text { "Some teachers will clearly outline } \\
\text { essential knowledge for their } \\
\text { courses...Personally, I think it is } \\
\text { useful for me to get key points and } \\
\text { learn faster..." Student } 2 \\
\text { "Teachers are just like } \\
\text { facilitators...um...who bring you into } \\
\text { this area...We have to dig our own } \\
\text { interests and direction." Student } 3\end{array}$ & $\begin{array}{l}\text { "In the beginning, students think } \\
\text { what they learn is what I } \\
\text { teach...later in their studies, they } \\
\text { gradually know teachers are just like } \\
\text { guiders. They have to cultivate self- } \\
\text { regulated ability if they want to work } \\
\text { in this area in the future." Teacher C }\end{array}$ \\
\hline
\end{tabular}


Students and teachers have consistent opinions about the value of diploma certificates. They do not perceive diploma certificates to be very important or highly valued in SE education, because the current Chinese software industry emphasizes comprehensive abilities more such as practical experience, technical knowledge and skills, and cooperation in teamwork.

The most of interviewees did not perceive the direct connection between education and social status or family honor. In contrast, a culture of individualism is reflected in student descriptions about the purposes of accepting SE education at universities. All students indicated that they wish to obtain professional knowledge and skills from the SE program for personal competence and growth. Two students believed they would have a better a life as a result of SE education.

\section{2) Masculinity}

The masculine culture of Chinese society appeared to be valid in current learning contexts of undergraduate SE education in China. This is reflected in learning environments that have become more competitive and stressful. Table $\mathrm{X}$ shows example reflections from the interviews. Four of the five students thought good grades are important, and two of them indicate academic success directly affects their future plans in the short or long term. Though the most of students agreed that competition in the SE program is intense, they did not directly express that they enjoy competing with others. However, many of them compete with themselves to attain the necessary competencies.

TABLE X. REFLECTIONS ON MASCULINE CULTURE

\begin{tabular}{|c|c|}
\hline $\begin{array}{c}\text { Teacher-student } \\
\text { interactions in learning }\end{array}$ & Interview reflections \\
\hline $\begin{array}{l}\text { Students care about } \\
\text { academic success }\end{array}$ & $\begin{array}{l}\text { "I think getting good grades is very important. It } \\
\text { is a way to show your performance." Student } 5 \\
\text { "I think academic success is relatively } \\
\text { important...For practical purposes, in the short } \\
\text { term, our university rewards good students with } \\
\text { scholarships. These are largely based on final } \\
\text { grades at the end of the semester. The positions } \\
\text { are limited." Student } 1 \\
\text { "I think grades are relatively important. I am } \\
\text { preparing to apply for a master's degree in the } \\
\text { near future. Academic performance is used to } \\
\text { select candidates." Student } 4\end{array}$ \\
\hline $\begin{array}{l}\text { Students compete in the } \\
\text { learning environment }\end{array}$ & $\begin{array}{l}\text { "In our university, I do not feel students want to } \\
\text { compete with others to make themselves } \\
\text { visible... um... Maybe the learning environments } \\
\text { are competitive. Those could be driven by, for } \\
\text { example, public comparison like ranking students } \\
\text { by grades and the pressure to apply to master's } \\
\text { degree studies or finding good jobs." Teacher C } \\
\text { "In this area... I do not think it necessarily means } \\
\text { you obtain the competencies through competition. } \\
\text { We have to find the direction to study further and } \\
\text { accumulate knowledge and experience in order to } \\
\text { adapt to completive environments..." Student } 4\end{array}$ \\
\hline
\end{tabular}

\section{3) Uncertainty avoidance}

In line with the results of the SLR, it is relatively difficult to measure whether Weak or Strong Uncertainty Avoidance characterizes teacher-student interaction patterns in undergraduate SE education in Chinese universities. The teachers and the students reflected both Weak and Strong Uncertainty Avoidance in current SE learning contexts. Table $\mathrm{XI}$ includes example reflections by the interviewees related to both Weak and Strong Uncertainty Avoidance cultural dimension. Conflict exits in "teachers are supposed to have the right answers." All interviewees held different opinions reflecting Weak Uncertainty Avoidance culture.

TABLE XI. REFLECTIONS ON UNCERTAINTY AVOIDANCE

\begin{tabular}{|c|c|}
\hline \multicolumn{2}{|c|}{ Weak Uncertainty Avoidance } \\
\hline $\begin{array}{l}\text { Students expect to have } \\
\text { unstructured learning experiences } \\
\text { assigned with vague learning } \\
\text { objectives }\end{array}$ & $\begin{array}{l}\text { "Generally, students have more than } \\
10 \text { classes per week, each class lasting } \\
100 \text { minutes...um... but for me, I have } \\
\text { around } 16 \text { classes...I try to make my } \\
\text { schedule strict..." Student } 2\end{array}$ \\
\hline $\begin{array}{l}\text { Teachers are expected to regulate } \\
\text { their emotions in accordance with } \\
\text { professional and ethical norms }\end{array}$ & $\begin{array}{l}\text { "It is the professional ethic to } \\
\text { maintain positive emotions. We are } \\
\text { teachers who communicate with } \\
\text { students face-to-face...If we bring } \\
\text { negative emotions into classrooms, we } \\
\text { may influence students." Teacher A }\end{array}$ \\
\hline "Teachers can say 'I do not know"” & $\begin{array}{l}\text { "How can a person know everything?" } \\
\text { Student } 3 \\
\text { "Teachers know more than me, but } \\
\text { that does not necessarily mean they } \\
\text { know all the answers." Student } 4 \\
\text { "Well, how could I know all the } \\
\text { answers...I do not know if they will } \\
\text { expect this... Generally, we will discuss } \\
\text { the problems together to find solutions. } \\
\text { It is not the pattern that they ask me, } \\
\text { and I tell them." Teacher C }\end{array}$ \\
\hline \multicolumn{2}{|c|}{ Strong Uncertainty Avoidance } \\
\hline $\begin{array}{l}\text { Students expect to have structured } \\
\text { learning experiences assigned with } \\
\text { strict learning schedule and detailed } \\
\text { assignments }\end{array}$ & $\begin{array}{l}\text { "I have...um ...probably about } 10 \text { to } \\
12 \text { courses per week. Each course } \\
\text { lasts around } 100 \text { minutes...I think } \\
\text { this schedule works for me, though it } \\
\text { seems strict for others." Student } 3 \\
\text { "Teachers will pick up some } \\
\text { exercises from course books...there } \\
\text { are detailed requirements for those } \\
\text { exercises...Sometimes teachers will } \\
\text { modify those exercises depending on } \\
\text { what they teach on the course." } \\
\text { Student } 5\end{array}$ \\
\hline
\end{tabular}

\section{FINDINGS}

The results of this study indicate that teacher-student interaction patterns in Chinese undergraduate SE education appear to be mostly consistent with prior studies, which indicate that teacher-student interaction patterns are influenced by Chinese cultural factors related to High Power Distance, Collectivism, and Masculinity cultural dimensions. 
However, there seem to be some differences in teacherstudent interactions in learning contexts of Chinese SE education. The first aspect concerns the changing learning styles and behavior in SE education. Though SE students are likely to dependent on teachers at the beginning, they would gradually cultivate self-learning and self-thinking skills with the studying year increase. The second aspect concerns the changed motivation and the purpose to get SE education. Prior research indicates that education in China promises to help students gain higher social status and bring honor to their family. In contrast, SE students want to obtain professional knowledge and technical skills in order to attain personal competence and growth. The third aspect concerns the changing roles of teachers and students. In Chinese SE education, the role of teachers is gradually transforming from "knowledge transfer" to "facilitators", and students are attempting to be more active in learning activities.

Factors contributing to the changes of teacher-student interaction patterns in Chinese undergraduate SE education could be the novel nature of the SE discipline and the trend of learning from Western countries; as Teacher B describes, "Our $\mathrm{SE}$ education program is frequently formed and regulated. We normally reform and regulate it based on previous experience and the reference of Western universities." The SE discipline is rapidly evolving, as new approaches, models and techniques are emerging in SE area. In order to adapt to the changing environment, software engineers are expected to have not only practical knowledge and skills but also the capabilities of independent thinking and self-learning. These relate to the expected learning outcomes of SE education in global contexts. Additionally, Western ideas and pedagogy are reflected in the changes. For example, teachers encourage students to think and learn independently through active learning in SE education.

However, teacher-student interaction patterns in Chinese SE education are still different from those in most Western education, which are characterized by Low Power Distance, Individualism, and Femininity culture [18]. There are many examples to illustrate the differences. Chinese pedagogy emphasizes harmony and stable interpersonal relationships in teacher-student interactions, while Western pedagogy promotes the conflicts to bring about new ideas [23]. Teachers may bear the responsibility of initiating communication with Chinese SE students, while students are encouraged to initiate communication in most Western learning contexts. Western teacher-student interaction encourages active learning toward more self-learning and self-thinking skills in SE education [24], while increasing interaction in Chinese classrooms is relatively difficult, because of the large classes coupled with limited time and resources.

\section{THREATS TO VALIDITY}

In the SLR, the search string may not have covered all prior research in the relevant educational areas, even though informatics professionals were consulted in the planning of the literature search. Because this study covers many disciplines, including SE, education science, and cultural and regional studies, it is challenging to comprehensively cover all potentially relevant sources. Moreover, for consistency, the studies were limited to English language papers, although many relevant papers have been published in Chinese.

At interview stage, the small number of participants and the confined area of the interviewees may limit the coverage and generalizability of the interviews results. Participating teachers can be expected to have relevant experience relating to the topic of the study, as they were senior SE teachers at NJIT with teaching experience ranging from 4-22 years. Additionally, as the interviews were conducted in Chinese, there may be inaccuracies in translating the responses of the interviewees.

\section{DISCUSSION AND CONCLUSION}

This study conducted SLR to identify Chinese cultural factors that influence teacher-student interaction patterns in Chinese learning contexts, and then validate those cultural factors in the current contexts of Chinese undergraduate SE education through interviews with students and teachers from NJIT. The results of the study are concluded there by answering the research questions.

RQ1: Based on prior research, what cultural factors influence teacher-student interaction patterns in Chinese learning contexts?

According to the literature, teacher-student interaction patterns are influenced by Chinese cultural factors related to High Power Distance, Collectivism, and Masculinity cultural dimensions. High Power Distance culture is manifest as "teacher-centered education", "students respect teachers", and also "teachers define learning paths for students". Collectivism culture is manifested as the stable and harmony relationships between teachers and students in learning situations, students rely on teachers, the enjoyment of collaboration, and practical purposes of education like getting higher social status and honor to family. Masculinity is manifested as Chinese learning contexts are highly driven by competition and achievement.

RQ2: Do the identified cultural factors influence teacherstudent interaction patterns in the current learning contexts of Chinese undergraduate SE education?

The teacher-student interaction patterns in Chinese undergraduate SE education appear to be mostly consistent with what was described in prior research. However, there are some differences. Some identified teacher-student interaction patterns from interviews would reflect the western ideas and cultures. For example, Chinese SE students are able to notice the importance of self-learning and self-thinking in SE learning with the studying year increase, teachers encourage students to learn and think independently, and SE education is mostly considered as the way to obtain professional knowledge and technical skills. This concerns about the changing learning styles and behaviors, the changing roles of teachers and students in SE education, and changed motivation and the purpose to get SE education. A possible reason could be the trend of learning from Western countries, and also novel nature of the SE discipline that requires SE students to cultivate self-learning and independent thinking skills as 
learning outcomes, and obtain personal competence to work in software industry.

The differences in teacher-student interaction patterns are likely to be a challenge when involving both Chinese and Western universities in cross-cultural learning situations of international collaborative SE education. When each side of participants aware of the differences between their own culture and others' culture, they would know more about what they would need to build on the exiting things, and what would be changed to establish effective and suitable teacherstudent interaction patterns in learning situations.

International collaborative education programs is adopting the distance learning model, which has advantages such as reducing travel costs, increased flexibility, and the ability to reach a large number of students globally. Distance learning requires more self-regulated and independent learning. However, some identified cultural factors of this study indicate that Chinese SE students are able to cultivate selflearning and self-thinking abilities in SE education. Therefore, it becomes the possible to adopt distance learning model in an international collaborative SE education program in China.

This study contributes to research on internationalization in SE education. The study results could be used to, for example, analyze the differences in teacher-student interaction between Chinese SE education and Western SE education, investigate the differences between Chinese and Western pedagogy in SE education, and also identify cross-cultural challenges in international collaborative SE education.

Future research could explore to the utilization of the identified cultural factors in the cultural sensitive design of an international collaborative SE education program. Additionally, the results of this study require more empirical research to complement. The ways to establish effective teacher-student interaction patterns in different learning environments are also expected to be investigated.

\section{ACKNOWLEDGMENTS}

We would like to thank Nanjing Institute of Technology University in China for arranging the interviews.

\section{REFERENCES}

[1] W. J. Kramer, B. Jenkins, and R. S. Katz, "The role of the information and communications technology sector in expanding economic opportunity," Cambridge, MA: Kennedy School of Government, Harvard University, 2007.

[2] R. Yang, Third Delight: The Internationalization of Higher Education in China, Psychology Press, 2002.

[3] M. G. Hilgers, B. B. Flachsbart, and C. C. Elrod, "Collaborative international education: reaching across borders," Multicultural Education \& Technology Journal, vol. 6, pp. 45-56, 2012.

[4] Ministry of Education of the people's Republic of China, "Approved international collaborative programs in 2017," vol. 2017, Jul 20, 2017.
[5] F. Huang, "Internationalization of higher education in the developing and emerging countries: A focus on transnational higher education in Asia," Journal of Studies in International Education, vol. 11, pp. 421432, 2007.

[6] P. Parrish and J. Linder-VanBerschot, "Cultural dimensions of learning: Addressing the challenges of multicultural instruction," The International Review of Research in Open and Distributed Learning, vol. 11, pp. 1-19, 2010

[7] IEEE Standard Glossary of Software Engineering Terminology, ANSI/IEEE Std 610.12-1990.

[8] The Joint Task Force on Computing Curricula - ACM/IEEE-Computer Society. Computer Science Curricula 2013: Curriculum Guidelines for Undergraduate Degree Programs in Computer Science. 2013.

[9] B.S. Bloom, M.D. Engelhart, E.J. Furst, W.H. Hill, and D.R. Krathwohl, "Taxonomy of Educational Objectives: The Classification of Educational Goals, " Handbook I: Cognitive Domain, New York: David McKay Company, Inc. (7th Edition 1972), 1956.

[10] A. J. Rhem, Knowledge Management in Practice, 1st ed, 2016.

[11] R. Phillips, C. McNaught, and G. Kennedy, "Towards a generalised conceptual framework for learning: the Learning Environment, Learning Processes and Learning Outcomes (LEPO) framework," 2010.

[12] Hidden curriculum (2014, August 26). "The glossary of education reform", Accessed on: April. 1, 2017, [Online] Available: http://edglossary.org/hidden-curriculum

[13] D. Chalil, "Analyzing farmers' learning process in sustainable development: The case of organic paddy farmers in north sumatra, indonesia," in Handbook of Research on Pedagogical Innovations for Sustainable Development, Eds. Hershey, PA, USA: IGI Global, pp. 524542, 2014.

[14] J. P. Coyle et al, "Evaluation of course curriculum and teaching: Guidelines for higher education instructors," in Handbook of Research on Transnational Higher Education, Eds. Hershey, PA, USA: IGI Global, pp. 330-349, 2014.

[15] Y. Yang, M. Buchberger, and H. Y. Harrison, "Assessing general education outcomes across programs," in Handbook of Research on Practices and Outcomes in Virtual Worlds and Environments, Eds. Hershey, PA, USA: IGI Global, pp. 620-634, 2012.

[16] D. Bath and J. Bourke, "Blended Learning," Griffith University, 2010.

[17] D. McIlrath and W. Huitt, "The teaching-learning process: A discussion of models," Educational Psychology Interactive, 1995.

[18] G. Hofstede, "Cultural differences in teaching and learning," International Journal of Intercultural Relations, vol. 10, pp. 301-320, 1986

[19] N. Al-Huwail, S. Al-Sharhan, and A. Al-Hunaiyyan, "Learning design for a successful blended e-learning environment: Cultural dimensions," INFOCOMP Journal of Computer Science, vol. 6, pp. 6069, 2007.

[20] S. J. Ball, "Big policies/small world: An introduction to international perspectives in education policy," Comparative Education, vol. 34, pp. 119-130, 1998

[21] P. Sahlberg, "Education policies for raising student learning: The Finnish approach," Journal of Education Policy, vol. 22, pp. 147-171, 2007.

[22] B. Kitchenham, "Guidelines for performing systematic literature reviews in software engineering," in Technical Report, Ver. 2.3 EBSE Technical Report. EBSE, sn, 2007.

[23] C. M. Reigeluth and J. Moore, "Cognitive education and the cognitive domain," Instructional-Design Theories and Models: A New Paradigm of Instructional Theory, vol. 2, pp. 51-68, 1999.

[24] S. Freeman, S.L. Eddy, M. McDonough, M.K. Smith, N. Okoroafor, H. Jordt, and M.P. Wenderoth, "Active learning increases student performance in science, engineering, and mathematics," Proceedings of the National Academy of Sciences, vol. 111, pp. 8410-8415, 2014. 